Keywords: Hodgkin lymphoma; long-term complications; subsequent malignant neoplasms; cardiovascular disease; chemotherapy; radiation therapy

\title{
High burden of subsequent malignant neoplasms and cardiovascular disease in long- term Hodgkin lymphoma survivors
}

\author{
Simone de Vries ${ }^{1}$, Michael Schaapveld ${ }^{1}$, Frederika A van Nimwegen ${ }^{1}$, Katarzyna Jóźwiak ${ }^{1}$,
} Pieternella J Lugtenburg ${ }^{2}$, Laurien A Daniëls ${ }^{3}$, Judith M Roesink ${ }^{4}$, Richard W M van der Maazen ${ }^{5}$, Wouter E M Kok ${ }^{6}$, Berthe M P Aleman ${ }^{7}$ and Flora E van Leeuwen ${ }^{*}, 1$

\begin{abstract}
${ }^{1}$ Department of Epidemiology, The Netherlands Cancer Institute, Plesmanlaan 121, 1066 CX, Amsterdam, The Netherlands; ${ }^{2}$ Department of Hematology, Erasmus MC Cancer Institute, Wytemaweg 80, Rotterdam 3015 CN, The Netherlands; ${ }^{3}$ Department of Radiotherapy, Leiden University Medical Centre, Albinusdreef 2, Leiden 2333 ZA, The Netherlands; ${ }^{4}$ Department of Radiotherapy, University Medical Centre Utrecht, Heidelberglaan 100, Utrecht 3584 CX, The Netherlands; ${ }^{5}$ Department of Radiotherapy, Radboud University Medical Centre, Geert Grooteplein Zuid 10, Nijmegen 6525 GA, The Netherlands; ${ }^{6}$ Department of Cardiology, Academic Medical Center, Meibergdreef 9, Amsterdam 1100 DD, The Netherlands and 7 Department of Radiation Oncology, The Netherlands Cancer Institute, Plesmanlaan 121, Amsterdam 1066 CX, The Netherlands
\end{abstract}

Background: Hodgkin lymphoma $(\mathrm{HL})$ patients are at an increased risk of late adverse treatment effects. While published studies focussed on the risk of either subsequent malignant neoplasms (SMNs) or cardiovascular disease (CVD), we examined the combined burden from SMN and CVD.

Methods: In 2908 5-year HL survivors treated between 1965 and 2000, the burden from SMN and/or CVD was assessed using cumulative incidences (Cls) and the mean cumulative count (MCC).

Results: We identified 888 SMNs and 1153 CVDs in 1247 patients (median follow-up 22 years). At 40 years, the Cl for developing either SMN or CVD was 68\% and the CI for developing both SMN and CVD was 17\%, and an average of 1.2 events per patient (MCC) was observed. HL patients who developed a solid malignancy had similar 15-year risks to develop another subsequent malignancy or CVD (15\%), whereas patients who developed a CVD after HL had a higher 15-year risk to develop another CVD compared with a subsequent malignancy (46 vs 15\%). Radiotherapy was the strongest risk factor for developing both SMN and CVD in multivariable Cox regression models.

Conclusions: Treating physicians should be aware of the increased risk of both SMN and CVD in patients treated for HL until 2000.

Survival following Hodgkin lymphoma (HL) has improved significantly over the past decades because of the development of more effective radiotherapy (RT) and chemotherapy (CT) regimens (Borchmann et al, 2012). The current 10-year survival rates exceed $80 \%$, leading to increasing numbers of HL survivors. Unfortunately, improved survival has been accompanied by late adverse events related to treatment (Hancock et al, 1993; van
Leeuwen et al, 2000; Dores et al, 2002; Ng et al, 2002b; Hull et al, 2003; Aleman et al, 2007; Hodgson et al, 2007; Swerdlow et al, 2007; Myrehaug et al, 2008; Galper et al, 2011; Swerdlow et al, 2011; Schaapveld et al, 2015; van Nimwegen et al, 2015), of which subsequent malignant neoplasms (SMNs) and cardiovascular diseases (CVDs) contribute most to excess morbidity and mortality (Ng et al, 2002a; Aleman et al, 2003).

*Correspondence: Dr FE van Leeuwen; E-mail: f.v.leeuwen@nki.nl

Received 18 September 2017; revised 4 December 2017; accepted 4 December 2017; published online 30 January 2018

(C) 2018 Cancer Research UK. All rights reserved 0007 - 0920/18 
Several studies reported that HL survivors have an increased incidence of SMN and CVD compared with the general population ( $\mathrm{Ng}$ et al, 2002b; Aleman et al, 2007; Hodgson et al, 2007; Galper et al, 2011; Swerdlow et al, 2011; Schaapveld et al, 2015; van Nimwegen et al, 2015). Moreover, recent studies suggest that these increased risks persist even more than 40 years after initial treatment for HL (Schaapveld et al, 2015; van Nimwegen et al, 2015). As HL often occurs at relatively young ages, these highly increased risks of late adverse events may pose a large burden on survivors. Until now, research has focussed on separate risk estimates for SMN and CVD and we are not aware of studies examining SMN and CVD as a combined end point in HL survivors. However, a proportion of HL survivors may develop both SMN and CVD - or even multiple SMNs or CVDs - leading to increased morbidity and mortality among these survivors.

This study examines the combined risk of SMNs and CVDs in a large cohort of HL survivors with long-term and complete followup, providing more insight into the total burden of morbidity from these late effects.

\section{PATIENTS AND METHODS}

Data collection procedures. We performed a cohort study in 2979 patients treated for HL in five university hospitals or cancer centres (The Netherlands Cancer Institute Amsterdam, the Erasmus MC Cancer Institute Rotterdam, Leiden University Medical Centre, Radboud University Medical Centre Nijmegen, and University Medical Centre Utrecht) in The Netherlands. The selection of patients has been described in detail previously (van Leeuwen et al, 1994, 2000; Aleman et al, 2003, 2007; De Bruin et al, 2009; van Eggermond et al, 2014). In brief, patients were below age 51 years at HL diagnosis, treated between 1965 and 2000, and had survived $\geqslant 5$ years after HL diagnosis.

From the medical records, the following information was collected: date of HL diagnosis; treatment modalities of primary and salvage treatment (i.e., radiation fields, chemotherapeutic agents, and number of cycles); dates of CVD diagnoses; dates of diagnoses of SMNs; and date of most recent medical information or date of death. Information on subsequent malignancies since 1989 was obtained by record linkage with the Netherlands Cancer Registry (Schaapveld et al, 2015). Vital status and dates of death were obtained through linkage with the Dutch Central Bureau for Genealogy. Additionally, follow-up data on CVDs and SMNs were retrieved by contacting the patients' general practitioners and cardiologists (van Nimwegen et al, 2015). Data on both SMN and CVD were complete until at least 31 December 2013. This study was exempt from institutional review board approval according to Dutch law because existing data from medical files were used.

The following cardiovascular events were included: coronary heart disease (CHD), including myocardial infarction (MI) and angina pectoris (AP); valvular heart disease (VHD); and heart failure (HF), including congestive heart failure (CHF) and cardiomyopathy (CMP). All events were defined and graded according to a slightly adapted version of the Common Terminology Criteria of Adverse Events, version 4.0 (69\% graded cardiovascular events). VHD with grade $1(n=83)$ was excluded from the analyses, because these events do not pose a large burden on patients. Additionally, we excluded VHD with unknown grade $(n=110)$ as we assumed, based on a previous case-control study, that many of such events were also grade 1 (Cutter et al, 2015). Consequently, the cardiovascular disease rates presented in this paper will be slightly conservative. To prioritise CVD events when multiple CVDs were diagnosed on the same date, decision rules were developed with a cardiologist (WEMK; Supplementary Methods I). In short, CHD was prioritised over VHD and HF, and HF over VHD. Only one VHD was considered in the analysis; we included multiple MIs if the interval between two MIs was $\geqslant 3$ months. The AP following a MI diagnosis was included when the interval between the two events was $\geqslant 6$ months. We included all invasive SMNs in the analyses, except basal cell carcinomas of skin. Subsequent malignancies occurring in paired organs were included if the latter was not considered to be a recurrence of the previous malignancy. Both incident and fatal SMNs and CVDs were included.

Treatment. Over time, a wide variety of treatment regimens was used, although most patients were treated according to the European Organisation for Research and Treatment of Cancer Lymphoma Group protocols (Carde et al, 1988; Raemaekers et al, 2002; Eghbali et al, 2005). Earlier reports have described frequently used treatments and changes over time (Aleman et al, 2007; van Eggermond et al, 2014). Patients treated with radiotherapy alone usually received 40 Gray (Gy) in fractions of 1.5-2.0 Gy, whereas patients who also received chemotherapy received $30-36 \mathrm{~Gy}$ in similar fractions. Individual shielding was used to limit normal tissue exposure as much as possible. Mantle field irradiation (including mediastinal, axillary, and neck nodes) was the most common supradiaphragmatic radiation field applied from the early 1970s to the late 1980s. Since then, an increasing number of patients received more limited radiation fields (involved field radiation).

From the 1960s to the 1980s, chemotherapy for HL mainly consisted of MOPP (mechloretamine, vincristine, procarbazine, prednisone). In the 1980s, anthracycline-containing regimens, such as MOPP/ABV (mechloretamine, vincristine, procarbazine, prednisone/doxorubicin, bleomycin, vinblastine) and ABVD (doxorubicin, bleomycin, vinblastine, dacarbazine), were introduced as a part of primary treatment. More detailed information on main radiotherapy fields and anthracyclines stratified by treatment period are presented in Supplementary Table 1.

Statistical analysis. Patients were categorised into treatment groups based on radiation fields and chemotherapy regimens administered in both primary and salvage treatment (Supplementary Methods II). To assess the risk of SMN and CVD, the following outcome measures were used: diagnosis of either SMN or CVD as first event, and diagnosis of both SMN and CVD. When examining the risk of developing SMN or CVD, time at risk began 5 years after the start of initial HL treatment and ended at date of diagnosis of either SMN or CVD, date of most recent medical information, date of migration, or date of death, whichever came first. When analysing the development of both SMN and CVD as the outcome, time at risk ended at date of diagnosis of the last of the two events. Patients diagnosed with a SMN or CVD before or within 5 years after HL diagnosis $(n=9$ and $n=62$, respectively) were excluded (Supplementary Methods III).

The burden from SMN and CVD events in our cohort was assessed in three different ways. First, the cumulative incidences (CIs) of either SMN or CVD as first event, and of development of both SMN and CVD, was estimated in the presence of death as competing risk. Second, the cumulative incidence of developing at least one, two, three, or four events was estimated. Third, we used the method of mean cumulative count (MCC) to take all SMN and CVD events in our cohort into account (Dong et al, 2015). The MCC reflects the average number of events of interest per individual in a population within a given period of time, taking both first and subsequent events into account. Patients who experience an event (or multiple events) remain in the risk set until they either experience a competing risk (death) or are censored. In this analysis, all SMN and CVD events were taken into account.

We performed multivariable Cox regression analyses to quantify the effects of HL treatments on the risk of SMN or CVD as first event and the risk of both SMN and CVD. The proportional hazards assumption was assessed using residual-based methods. An interaction term of age at HL treatment and time was included in the Cox 
Table 1. Characteristics of all Hodgkin lymphoma patients and patients with SMN and/or CVD

\begin{tabular}{|c|c|c|c|c|c|c|}
\hline & \multicolumn{2}{|c|}{$\begin{array}{l}\text { Total cohort } \\
(n=2908)\end{array}$} & \multicolumn{2}{|c|}{$\begin{array}{l}\text { Patients with SMN or } \\
\text { CVD }^{a}(n=1247)\end{array}$} & \multicolumn{2}{|c|}{$\begin{array}{l}\text { Patients with SMN } \\
\text { and CVD }(n=240)\end{array}$} \\
\hline & $N$ & $\%$ & $N$ & $\%$ & $N$ & $\%$ \\
\hline \multicolumn{7}{|l|}{ Sex } \\
\hline Male & 1636 & 56.3 & 684 & 54.9 & 112 & 46.7 \\
\hline Female & 1272 & 43.7 & 563 & 45.2 & 128 & 53.3 \\
\hline \multicolumn{7}{|c|}{ Age at first $\mathrm{HL}$ treatment (years) } \\
\hline Median (IQR) & 27.3 & $21.6-35.3$ & 28.9 & $22.3-37.5$ & 30.4 & $23.3-37.4$ \\
\hline$<25$ & 1165 & 40.1 & 445 & 35.7 & 79 & 32.9 \\
\hline $25-34$ & 987 & 33.9 & 411 & 33.0 & 79 & 32.9 \\
\hline $35-50$ & 756 & 26.0 & 391 & 31.4 & 82 & 34.2 \\
\hline \multicolumn{7}{|l|}{ Treatment period } \\
\hline 1965-1976 & 786 & 27.0 & 493 & 39.5 & 118 & 49.2 \\
\hline 1977-1988 & 1077 & 37.0 & 530 & 42.5 & 103 & 42.9 \\
\hline 1989-2000 & 1045 & 35.9 & 224 & 18.0 & 19 & 7.9 \\
\hline \multicolumn{7}{|l|}{ Follow-up time (years) } \\
\hline Median (IQR) & 21.8 & $15.9-29.4$ & 25.7 & $18.8-32.9$ & 29.9 & $24.3-37.3$ \\
\hline $5-9$ & 280 & 9.6 & 72 & 5.8 & 4 & 1.7 \\
\hline 10-19 & 985 & 33.9 & 292 & 23.4 & 29 & 12.1 \\
\hline $20-29$ & 957 & 32.9 & 457 & 36.7 & 90 & 37.5 \\
\hline $30-39$ & 547 & 18.8 & 327 & 26.2 & 79 & 32.9 \\
\hline$\geqslant 40$ & 139 & 4.8 & 99 & 7.9 & 38 & 15.8 \\
\hline \multicolumn{7}{|l|}{ Treatment category } \\
\hline Radiotherapy only & 789 & 27.1 & 434 & 34.8 & 105 & 43.8 \\
\hline Chemotherapy only & 202 & 7.0 & 51 & 4.1 & 4 & 1.7 \\
\hline Radiotherapy and chemotherapy & 1917 & 65.9 & 762 & 61.1 & 131 & 54.6 \\
\hline \multicolumn{7}{|l|}{ Relapse } \\
\hline Yes & 835 & 28.7 & 377 & 30.2 & 69 & 28.7 \\
\hline No & 2073 & 71.3 & 870 & 69.8 & 171 & 71.3 \\
\hline \multicolumn{7}{|l|}{ Radiotherapy fields ${ }^{b}$} \\
\hline Limited radiation fields & 146 & 5.0 & 31 & 2.5 & 3 & 1.3 \\
\hline Inverted-Y & 133 & 4.6 & 43 & 3.5 & 6 & 2.5 \\
\hline Incomplete mantle field & 470 & 16.2 & 131 & 10.5 & 22 & 9.2 \\
\hline Mantle field & 713 & 24.5 & 383 & 30.7 & 83 & 34.6 \\
\hline Incomplete subtotal nodal & 237 & 8.2 & 92 & 7.4 & 15 & 6.3 \\
\hline Subtotal nodal & 747 & 25.7 & 409 & 32.8 & 87 & 36.3 \\
\hline Total nodal & 203 & 7.0 & 96 & 7.7 & 18 & 7.5 \\
\hline Fields unknown & 57 & 2.0 & 11 & 0.9 & 2 & 0.8 \\
\hline No radiotherapy & 202 & 7.0 & 51 & 4.1 & 4 & 1.7 \\
\hline \multicolumn{7}{|l|}{ Chemotherapy } \\
\hline No anthracyclines & 961 & 33.1 & 487 & 39.1 & 99 & 41.3 \\
\hline Anthracyclines & 1158 & 39.8 & 326 & 26.1 & 36 & 15.0 \\
\hline Median dose (IQR), $\mathrm{mg} \mathrm{m}^{-2}$ & 210 & $150-280$ & 210 & $210-300$ & 280 & $210-300$ \\
\hline No procarbazine & 581 & 20.0 & 249 & 20.0 & 50 & 20.8 \\
\hline$\leqslant 4.2 \mathrm{~g} \mathrm{~m}^{-2}$ procarbazine dose & 612 & 21.1 & 188 & 15.1 & 20 & 8.3 \\
\hline$>4.2 \mathrm{~g} \mathrm{~m}^{-2}$ procarbazine dose & 926 & 31.8 & 376 & 30.2 & 65 & 27.1 \\
\hline No chemotherapy & 789 & 27.1 & 434 & 34.8 & 105 & 43.8 \\
\hline \multicolumn{7}{|c|}{ 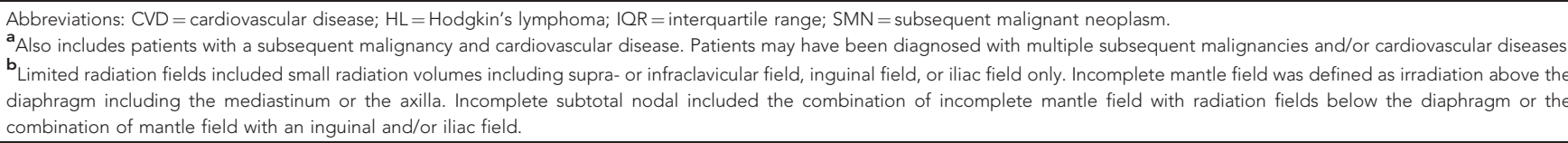 } \\
\hline
\end{tabular}

regression models, because hazards were non-proportional by age. Additionally, models were adjusted for sex. Interaction between radiotherapy and chemotherapy was assessed using standard methods. The $P$-values of $<0.05$ were considered statistically significant. Analyses were performed using Stata statistical software, version 13 (StataCorp, College Station, TX, USA).

\section{RESULTS}

In total, 2908 5-year HL survivors were included in the analyses. Median age at HL treatment was 27.3 years (Table 1). In the majority of patients, treatment for HL consisted of radiotherapy alone $(27.1 \%)$, or in combination with chemotherapy (65.9\%). Among patients treated with radiotherapy, $25.7 \%$ received subtotal nodal irradiation, $24.5 \%$ received mantle field irradiation, and $16.2 \%$ received other supradiaphragmatic radiation fields. After a median follow-up of 21.8 years, we identified 888 SMNs and 1153 CVDs in 1247 patients; 240 patients developed both SMN and CVD. Median age at first event was 49.8 years (interquartile range $(\mathrm{IQR})=42.4-56.5$ ) and patients with both an SMN and CVD had a median age of 56.9 years (IQR $=49.4-63.8)$ at diagnosis of the second event. Of all patients who developed a SMN or CVD, 270 patients developed a subsequent event and 160 patients even developed two subsequent events. 


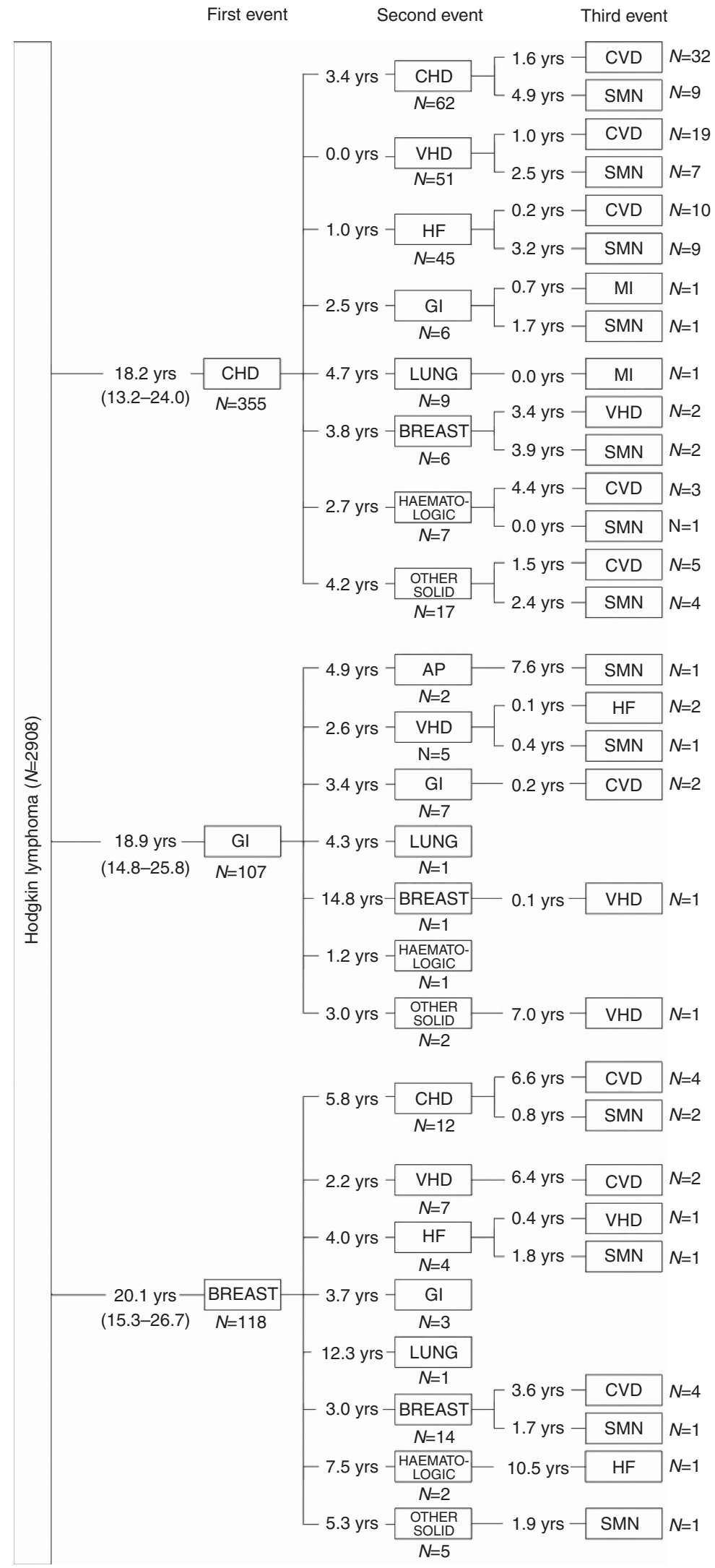

Figure 1. Flowchart of subsequent malignancies and cardiovascular diseases in Hodgkin lymphoma survivors. Subsequent events are shown when the first event is coronary heart disease (CHD; including both myocardial infarction and angina pectoris, with $54 \%$ myocardial infarction among $\mathrm{CHD}$ as first event), gastrointestinal cancer (Gl; including all malignant neoplasms of digestive organs corresponding with ICD-10 codes C15-C26) and breast cancer (ICD-10 code C50). Subsequent events included valvular heart disease (VHD), heart failure (HF), lung cancer (ICD-10 codes C33-C34), haematologic cancer (ICD-10 codes C82-C96), and other solid malignancies. Median time between subsequent events expressed in years. $\mathrm{CVD}=$ cardiovascular disease; $\mathrm{SMN}=$ subsequent malignant neoplasm. 
Figure 1 illustrates the pattern of subsequent second and third SMN and CVD events following either CHD, gastrointestinal, or breast cancer as a first event and the time interval between these events. A total of 357 patients developed CHD after HL treatment, with a median time between HL and CHD diagnosis of 18.3 years $(\mathrm{IQR}=13.2-24.0)$. As most patients survive a CHD event, many subsequent events were observed in these patients. Following CHD diagnosis, 51 patients developed VHD and 45 patients HF. After a median follow-up of 20.1 years $(\mathrm{IQR}=15.3-26.7)$, a total of 118 patients developed breast cancer, of whom 14 developed another breast cancer (median interval 3.0 years; IQR $=0.9-7.7$ ) and 12 developed CHD (median interval 5.8 years; IQR $=3.1-9.2$ ). Few subsequent events were observed following cancers with a relatively poor prognosis, for example, gastrointestinal and lung cancer (Supplementary Figure 1).

Overall burden. At 40 years after HL, the cumulative incidence of developing either SMN or CVD was $67.8 \%(95 \% \mathrm{CI}=65.1-70.4)$; the cumulative incidence of developing both SMN and CVD was $17.2 \%$ (95\% CI $=15.0-19.6)$ (Figure $2 \mathrm{~A})$. Several patients developed either multiple SMNs or multiple CVDs, but not a SMN and a CVD (Figure 2B). At 40 years, the cumulative incidence for at least two events was $32.3 \%(95 \% \mathrm{CI}=29.5-35.1)$, whereas the cumulative incidences for at least three or four events were $12.5 \%$ $(95 \% \mathrm{CI}=10.6-14.6)$ and $2.6 \%(95 \% \mathrm{CI}=1.7-3.8)$, respectively. The MCC analysis, which takes all subsequent SMN and CVD events into account, showed that by 40 years after treatment an average of 122 events had occurred per 100 survivors $(\mathrm{MCC}=1.2)$ (Figure 2C). Patients who had relapsed were not at higher risk to develop SMN or CVD compared with patients who did not relapse (Supplementary Figure 2).

Patients treated at ages $\geqslant 35$ years had a higher cumulative incidence of SMN or CVD than patients treated at younger ages (Supplementary Figure 2). The 30-year cumulative incidence of SMN or CVD for patients treated at ages $\geqslant 35$ years was $62.5 \%$ $(95 \% \mathrm{CI}=58.1-66.6)$, whereas the 30-year cumulative incidence for patients treated at ages $25-34$ years was $52.4 \%(95 \% \mathrm{CI}=48.3-$ $56.4)$, and for patients $\leqslant 25$ years at treatment $43.8 \%(95 \%$ $\mathrm{CI}=40.2-47.4)$. The difference between these age groups was even more pronounced when we considered the MCC analysis. At 30 years since treatment, the mean number of events per 100 patients treated at ages $\geqslant 35$ years was twice that of patients $\leqslant 25$ years at treatment (50 vs 100 events). No clear differences were observed in the cumulative burden in different periods of diagnosis (Supplementary Figure 3).

Risk of subsequent events after a first SMN or CVD diagnosis. We assessed whether the risk of developing SMN or CVD as second event after HL - in this case as separate outcomes - differed between HL patients who first developed a solid SMN and those who first developed a CVD (Figure 3). The 15-year cumulative incidence of SMN was nearly identical after a solid SMN and after a CVD as first event $(15.8 \%, 95 \% \mathrm{CI}=12.2-19.7$, and $15.0 \%, 95 \%$ $\mathrm{CI}=11.8-18.6$, respectively). However, the 15 -year cumulative incidence for CVD as second event was much higher following a CVD as first event after HL $(46.1 \%, 95 \% \mathrm{CI}=41.3-50.7)$ than following a solid SMN as first event after HL (15.2\%, 95\% $\mathrm{CI}=11.7-19.0)$. This high cumulative incidence of a CVD following a previous CVD was most pronounced after $\mathrm{CHD}$ or VHD as first event after HL (Supplementary Figure 4).

Treatment-specific risks. Table 2 shows the results of multivariable Cox regression analyses for the risk of developing either SMN or CVD as a first event and for developing both SMN and CVD. Compared with patients receiving no or limited radiation fields, an increased risk of developing either SMN or CVD was observed for all radiotherapy fields including a supradiaphragmatic component. Mantle field radiotherapy was associated with a 2.6-
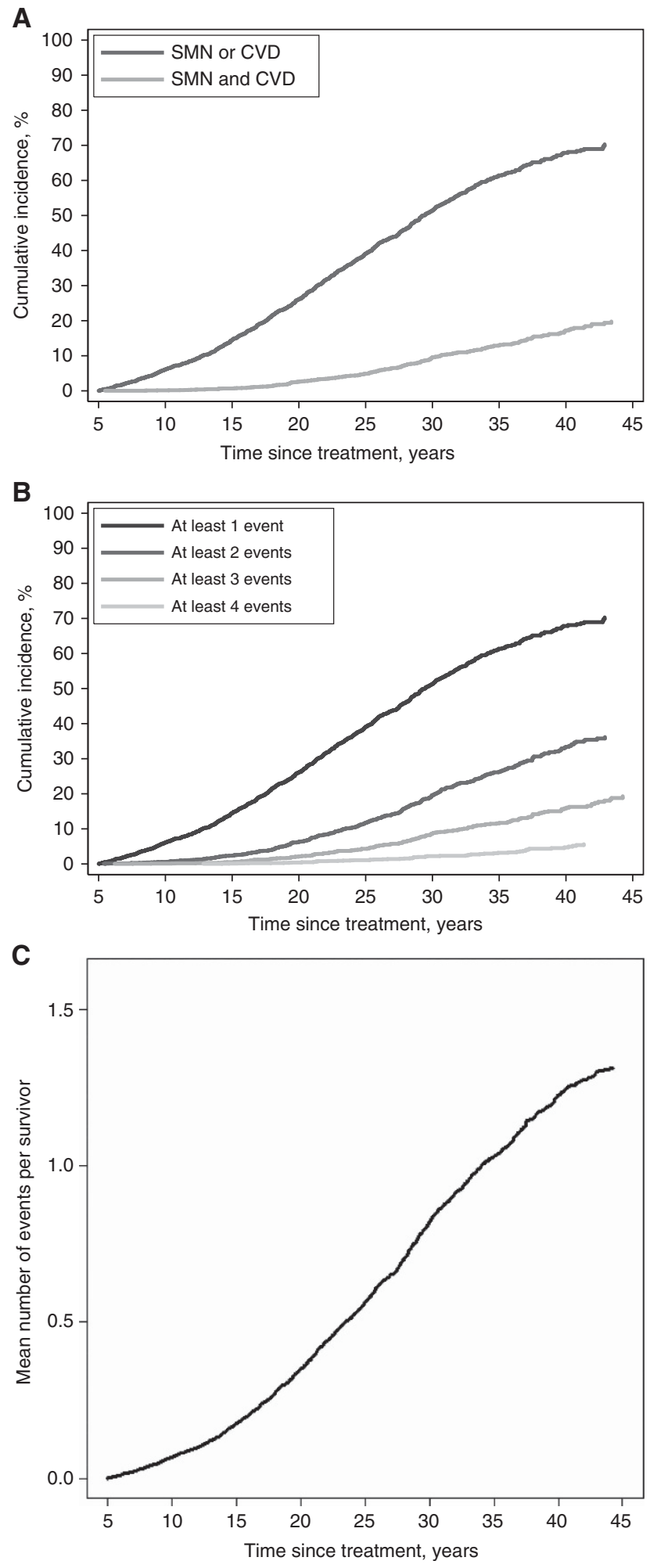

Figure 2. Different measures of the cumulative burden of subsequent malignancies and cardiovascular diseases in Hodgkin lymphoma survivors. (A) Overall cumulative incidence for developing subsequent malignancy (SMN) or cardiovascular disease (CVD) as first event and for developing both subsequent malignancy and cardiovascular disease. (B) Cumulative incidence for at least one, two, or three subsequent malignancies or cardiovascular diseases (irrespective of whether they concerned an SMN or CVD). (C) Overall mean cumulative count for all subsequent malignancies and cardiovascular diseases. 
fold increased risk to develop either SMN or CVD $(95 \% \mathrm{CI}=2.1-$ 3.4) and the risk was slightly higher in patients receiving more extensive radiotherapy fields including subtotal nodal and total nodal radiotherapy $(\mathrm{HR}=3.0,95 \% \mathrm{CI}=2.3-3.8$, and $\mathrm{HR}=2.7$, $95 \% \mathrm{CI}=2.0-3.7)$. Anthracycline-containing chemotherapy was associated with a 1.3-fold increased risk to develop either SMN or CVD $(95 \% \mathrm{CI}=1.1-1.5)$. No increased SMN or CVD risk was observed for high-dose procarbazine (i.e., $>4.2 \mathrm{~g} \mathrm{~m}^{-2}$ ) compared with low-dose procarbazine, other non-alkylating chemotherapy, or no chemotherapy. Separate models with SMN as first event or CVD as first event are presented in the Supplementary Table 2.

The risk of developing both SMN and CVD increased with larger radiotherapy volumes. An incomplete mantle field was associated with a 4.1-fold increased risk (95\% CI $=1.7-9.7)$, whereas (sub)total nodal radiotherapy increased the risk of developing both $\mathrm{SMN}$ and the CVD more than 6 -fold $(\mathrm{HR}=6.4$, $95 \% \mathrm{CI}=2.9-14.0)$. Chemotherapy was not associated with risk of developing both SMN and CVD.

Smoking was independently associated with increased risk of developing SMN or CVD $(\mathrm{HR}=1.4,95 \% \mathrm{CI}=1.2-1.6)$ and with development of both SMN and CVD $(\mathrm{HR}=1.6,95 \% \mathrm{CI}=1.2$ 2.1). We observed no interaction between radiotherapy and chemotherapy.

The cumulative burden of developing SMN or CVD was assessed for several radiotherapy regimens stratified for type of chemotherapy (Figure 4). Among patients who received no and no alkylating chemotherapy (except low-dose procarbazine), the cumulative incidence at 25 years was $15.5 \%(95 \% \mathrm{CI}=6.8-27.4)$ for no or limited radiotherapy. In contrast, the 25-year cumulative incidence of SMN or CVD for patients who received mantle field radiotherapy was $38.3 \%(95 \% \mathrm{CI}=33.0-43.7)$ and for subtotal nodal radiotherapy $47.9 \% \quad(95 \% \quad \mathrm{CI}=42.9-52.7)$. The MCC analysis showed the same pattern. Comparable cumulative incidences were observed for the different radiotherapy regimens among patients receiving high-dose procarbazine (Supplementary Figure 5). However, among patients who received anthracyclines, slightly higher risks of SMN or CVD were observed for the different radiotherapy regimens, compared with patients receiving no chemotherapy, low-dose procarbazine, high-dose procarbazine, or non-alkylating chemotherapy. Anthracyclines in combination with mantle field radiotherapy resulted in a 25 -year cumulative incidence of $51.4 \%$ (95\% CI $=42.2-59.8)$ and in combination with subtotal nodal radiotherapy in a cumulative incidence of $49.0 \%$ (95\% CI $=39.5-57.8)$.

\section{DISCUSSION}

With this study, we are the first to describe the combined burden from SMNs and CVDs in adolescent and young adult patients treated for HL. At 40 years of follow-up, the cumulative incidence of either SMN or CVD was $68 \%$ and the cumulative incidence of developing both a SMN and a CVD was $17 \%$. Taking all SMN and CVD events into account, every survivor had developed, on average, 1.2 events at 40 years of follow-up. The HL patients who developed a solid malignancy had similar 15-year risks to develop another subsequent malignancy or CVD (15\%), whereas patients who developed a CVD after HL had a higher 15-year risk to develop another CVD compared with a subsequent malignancy (46 vs $15 \%$ ). Both larger radiotherapy volumes and anthracyclinecontaining chemotherapy increased the risk of developing either SMN or CVD, whereas only supradiaphragmatic radiotherapy was associated with an increased risk of developing both SMN and CVD.

Several studies have examined the burden of disease in childhood cancer survivors (Oeffinger et al, 2006; Geenen et al, 2007; Hudson et al, 2013). Although these studies also observed a high disease burden among children treated for cancer, these findings are not directly comparable to the findings in our current study. In the childhood cancer survivor reports, all chronic conditions were taken into account, whereas we restricted our analyses to SMN and CVD as the most severe complications of HL

Table 2. Treatment-related risk factors for developing either subsequent malignancy and cardiovascular disease (as combined event) and for developing both subsequent malignancy and cardiovascular disease

\begin{tabular}{|c|c|c|c|c|}
\hline & \multicolumn{2}{|c|}{ SMN or CVD $(n=2851)$} & \multicolumn{2}{|c|}{ SMN and CVD $(n=2851)$} \\
\hline & $n / N$ & $\mathrm{HR}(95 \% \mathrm{Cl})$ & $n / N$ & $\mathrm{HR}(95 \% \mathrm{Cl})$ \\
\hline \multicolumn{5}{|l|}{ Radiotherapy ${ }^{a}$} \\
\hline $\begin{array}{l}\text { No or limited radiation exposure } \\
\text { Inverted-Y } \\
\text { Incomplete mantle field } \\
\text { Mantle field } \\
\text { Incomplete subtotal nodal } \\
\text { Subtotal nodal } \\
\text { Total nodal }\end{array}$ & $\begin{array}{c}82 / 348 \\
43 / 133 \\
131 / 470 \\
383 / 713 \\
92 / 237 \\
409 / 747 \\
96 / 203\end{array}$ & $\begin{array}{l}1.0 \text { (Ref.) } \\
1.2(0.8-1.7) \\
1.9(1.4-2.5) \\
2.6(2.1-3.4) \\
2.6(2.0-3.6) \\
3.0(2.3-3.8) \\
2.7(2.0-3.7)\end{array}$ & $\begin{array}{c}7 / 348 \\
6 / 133 \\
22 / 470 \\
83 / 713 \\
15 / 237 \\
105 / 950\end{array}$ & $\begin{array}{c}1.0 \text { (Ref.) } \\
1.9(0.6-5.6) \\
4.1(1.7-9.7) \\
5.9(2.7-13.0) \\
6.1(2.5-15.0) \\
6.4(2.9-14.0)\end{array}$ \\
\hline \multicolumn{5}{|l|}{ Chemotherapy regimen ${ }^{b}$} \\
\hline $\begin{array}{l}\text { No chemotherapy/low-dose procarbazine/other } \\
\text { Anthracyclines } \\
\text { High-dose procarbazine }\end{array}$ & $\begin{array}{c}651 / 1147 \\
324 / 1129 \\
261 / 575\end{array}$ & $\begin{array}{c}1.0 \text { (Ref.) } \\
1.3(1.1-1.5) \\
0.9(0.8-1.1)\end{array}$ & $\begin{array}{c}154 / 1147 \\
36 / 1129 \\
48 / 575\end{array}$ & $\begin{array}{l}1.0 \text { (Ref.) } \\
1.1(0.7-1.6) \\
1.0(0.7-1.3)\end{array}$ \\
\hline \multicolumn{5}{|l|}{ Smoking } \\
\hline $\begin{array}{l}\text { Never } \\
\text { Ever } \\
\text { Unknown }\end{array}$ & $\begin{array}{c}458 / 1266 \\
741 / 1408 \\
37 / 177\end{array}$ & $\begin{array}{c}1.0 \text { (Ref.) } \\
1.4(1.2-1.6) \\
0.9(0.6-1.2)\end{array}$ & $\begin{array}{c}80 / 1266 \\
156 / 1408 \\
2 / 177\end{array}$ & $\begin{array}{c}1.0 \text { (Ref.) } \\
1.6(1.2-2.1) \\
0.4(0.1-1.8)\end{array}$ \\
\hline \multicolumn{5}{|c|}{ 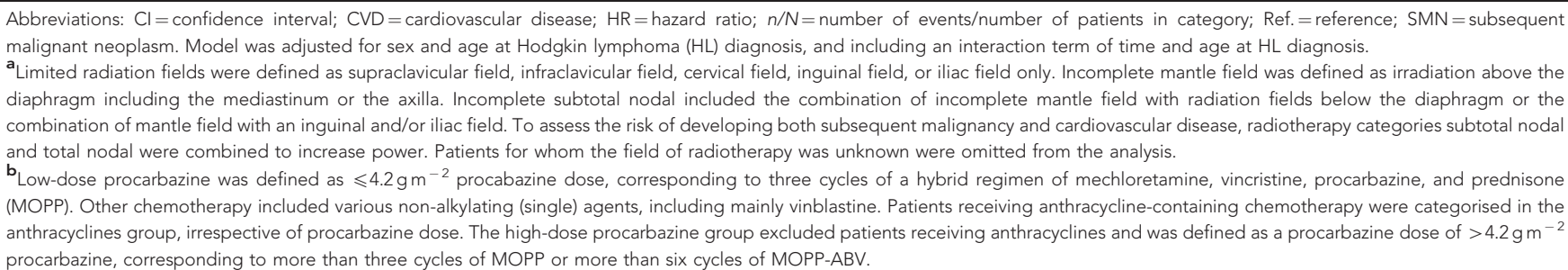 } \\
\hline
\end{tabular}



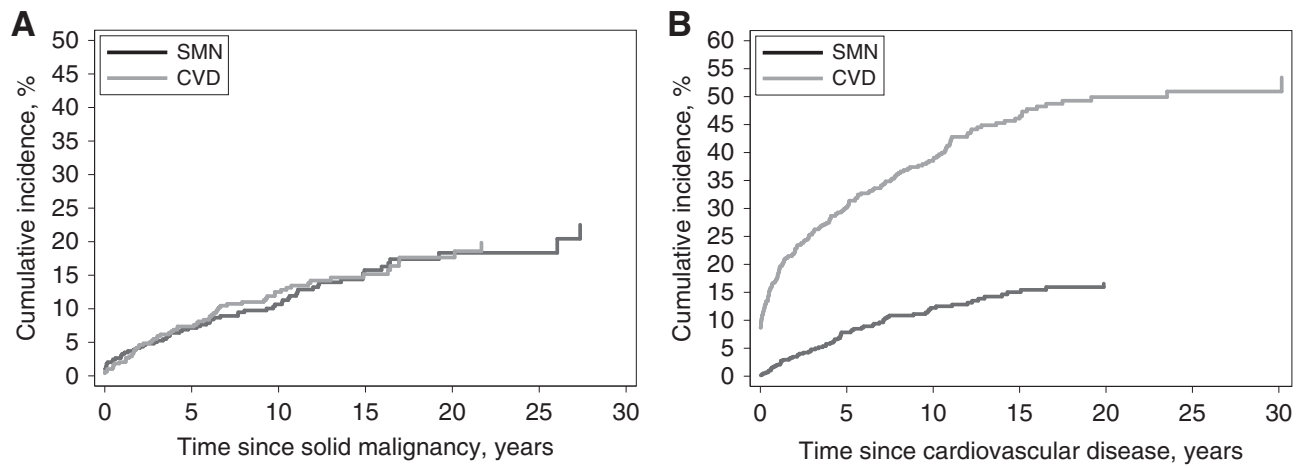

Figure 3. Cumulative incidence of subsequent malignancy and cardiovascular disease among survivors who developed a first event (solid malignancy or CVD) after Hodgkin lymphoma. (A) Cumulative incidence for developing subsequent malignancy (SMN) or cardiovascular disease (CVD) among survivors who developed a solid malignancy as first event. (B) Cumulative incidence for developing SMN or CVD among survivors who developed cardiovascular disease as first event.

treatment. A major difference relates to the assessment of adverse events. We obtained data on the incidence of SMNs and CVDs from hospital medical records, questionnaires to general practitioners, and linkage with the NCR. These data were prospectively collected for all patients during the course of follow-up. In the childhood cancer survivor reports, where chronic conditions were assessed through patient questionnaires or medical assessments, prevalence of disease was assessed in survivors who were still alive and responded to questionnaires or attended the clinic.

Unfortunately, this study could not compare the combined risk of SMN and CVD to that in the general population. No reference data are available that combine cancer and CVD rates. However, we know from previous studies assessing the risk of either SMN or CVD risk following HL that both these risks are increased compared with rates in the general population $(\mathrm{Ng}$ et al, 2002b; Aleman et al, 2007; Hodgson et al, 2007; Galper et al, 2011; Swerdlow et al, 2011; Schaapveld et al, 2015; van Nimwegen et al, 2015). From earlier studies we also know that HL patients have an increased risk to develop multiple SMNs or multiple CVDs related to treatment (Armstrong et al, 2011; van Eggermond et al, 2014; Bhakta et al, 2016). With respect to multiple SMN risk, it was found that HL patients who developed SMN remained at an increased risk to develop subsequent malignancies (Armstrong et al, 2011; van Eggermond et al, 2014). A recent paper showed that survivors of childhood HL are at increased risk to develop multiple CVDs, with five times more events at the same point during follow-up among HL survivors compared with community controls (Bhakta et al, 2016). These studies suggest that the burden of SMN and CVD is high among HL survivors; however, the combined risk of SMN and CVD was not previously described.

There are several statistical measures to assess disease burden in cohort studies. In this study, we used two different statistical methods. First, we calculated the cumulative incidence to develop $\mathrm{SMN}$ or CVD, and both SMN and CVD. Using cumulative incidence, patients are censored at the time of the first event of interest. Here, patients who experience a competing-risk event and patients experiencing the event of interest are removed from the risk set. We also determined the risk of developing one, two, three, or four events. Second, we used the method of mean cumulative count that provides the ability to take multiple, or recurring, events into account (Dong et al, 2015). Using MCC, patients can experience the event of interest multiple times and still remain at risk for subsequent events of interest. Here, we also took into account multiple CVDs according to our decision rules that in our opinion is important from a patient's perspective, as these events are probably associated with multiple visits to doctors, various treatments, and hospital admissions. The cumulative incidence and MCC reflect the burden of disease in a different way and we believe that both methods combined adequately reflect the total burden of SMN and CVD in our cohort.

We used the CTCAE to exclude VHD with grade 1 or unknown grade, because we wanted to restrict our analyses to more severe events. The CTCAE is frequently used to assess the severity of late complications of treatment. Especially for CVDs, CTCAE grading was useful; in our cohort, cardiovascular events with grade 2 mainly concerned angina pectoris and VHD. We did not take grade into account in our analyses, as for subsequent malignancies the CTCAE grading system is less informative as all SMNs are coded equally (i.e., grade 4), irrespective of topography, morphology, and stage. For example, stage I breast cancer has the same grade as stage III lung cancer. For future studies on burden from SMNs, we think a more precise grading system, that is, taking prognosis of subsequent malignancies into account, is needed.

The purpose of this study was to assess the total burden of morbidity from both SMN and CVD. When examining treatmentrelated risks on developing SMN and CVD as combined outcome, this means that if a certain treatment has a differential effect on the two outcomes, these effects may balance out in the analyses. For example, high-dose procabarzine increases the risk of gastrointestinal cancer (Morton et al, 2013; Schaapveld et al, 2015), whereas it decreases breast cancer risk (Travis et al, 2003; Swerdlow et al, 2012; Schaapveld et al, 2015). This may explain why we did not observe an increased risk of SMN and CVD after high-dose procarbazine.

Patients in our cohort were treated for HL between 1965 and 2000 according to treatment regimens commonly used in the Western world. Inherent to late effects research, many of those regimens are no longer commonly used. Over the past decades, effective chemotherapy was introduced that enabled reduction of radiotherapy volumes and dose, while maintaining high survival rates (Borchmann et al, 2012; Specht et al, 2014). In the current study, the highest risk of developing either SMN or CVD, or both SMN and CVD, was associated with large radiotherapy volumes that included a supradiaphragmatic field. Although the largest burden was posed by radiotherapy, anthracyclines were also associated with an increased SMN or CVD risk as combined outcome. We found no clear differences in the risk to develop either SMN or CVD by period of treatment. However, we expect that patients treated from 2000 onwards will experience a lower disease burden because of risk-adapted HL treatment (Engert et al, 2012; Andre et al, 2017), further reduction of radiotherapy volumes (Girinsky et al, 2006), and introduction of modern radiation techniques (Maraldo et al, 2015; Petersen et al, 2015).

In conclusion, HL patients treated between 1965 and 2000 experience a high disease burden from both SMN and CVD after HL treatment. Treating physicians should be aware that survivors 

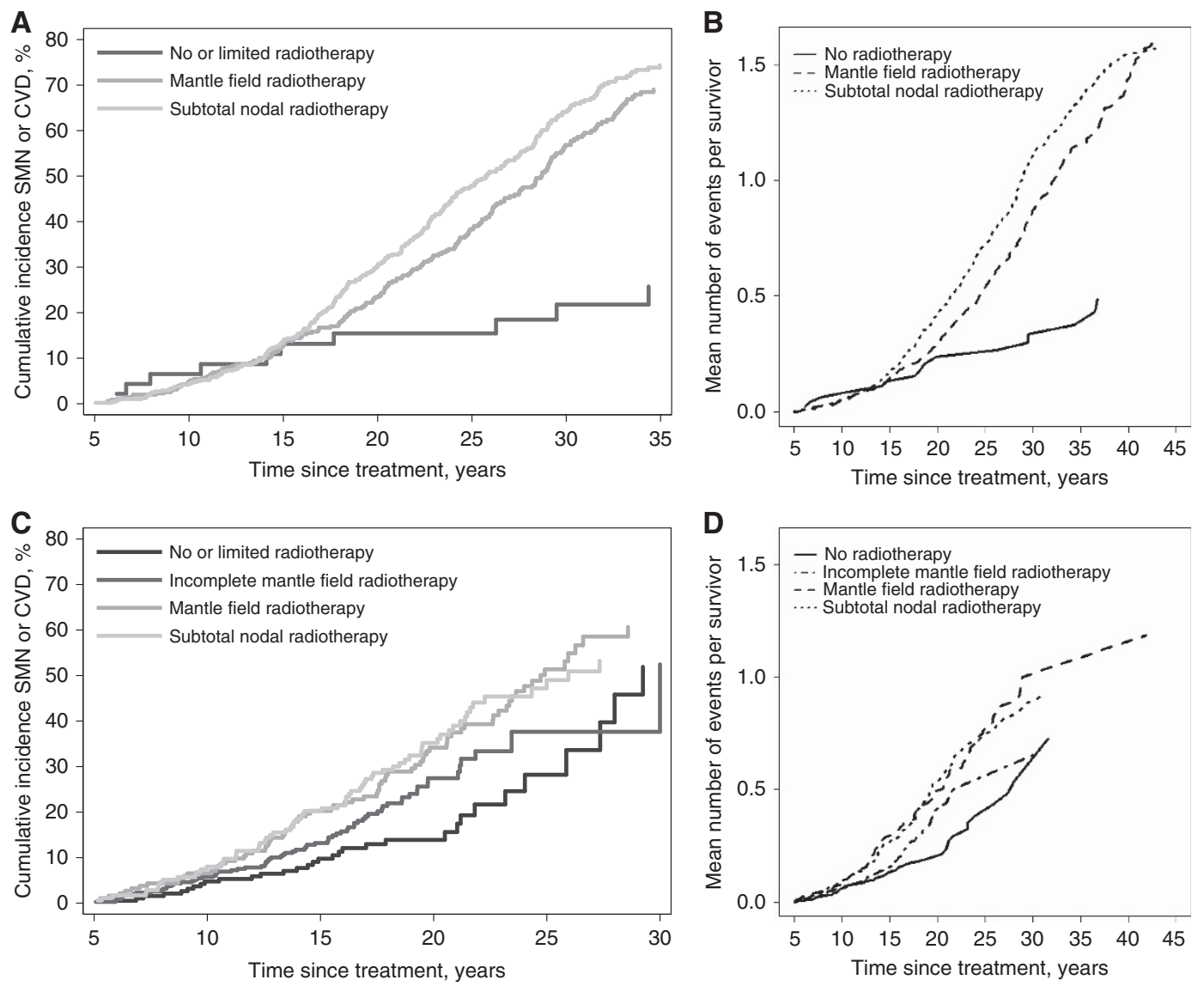

Figure 4. Different measures of the cumulative burden of subsequent malignancies and cardiovascular disease by treatment modality. For patients receiving no anthracyclines and no alkylating chemotherapy (except low-dose procarbazine), (A) the cumulative incidence of developing subsequent malignancy or cardiovascular disease as first event and (B) the mean cumulative count for all subsequent malignancies and cardiovascular diseases by radiotherapy field are shown. For patients receiving anthracycline-containing chemotherapy, (C) the cumulative incidence of developing subsequent malignancy or cardiovascular disease as first event and (D) the mean cumulative count for all subsequent malignancies and cardiovascular diseases by radiotherapy field are shown. Incomplete mantle field radiotherapy is only shown in the graphs for patients receiving anthracycline-containing chemotherapy because in the anthracycline era smaller radiotherapy fields were introduced.

diagnosed with a SMN or CVD also have a high risk of subsequent events, implying that expertise in cardio-oncology is crucial in the follow-up care of HL survivors.

\section{ACKNOWLEDGEMENTS}

This work was supported by the Dutch Cancer Society (NKI 2010$4720)$.

\section{CONFLICT OF INTEREST}

The authors declare no conflict of interest.

\section{REFERENCES}

Aleman BM, van den Belt-Dusebout AW, De Bruin ML, van 't Veer MB, Baaijens MH, de Boer JP, Hart AA, Klokman WJ, Kuenen MA, Ouwens GM, Bartelink H, van Leeuwen FE (2007) Late cardiotoxicity after treatment for Hodgkin lymphoma. Blood 109(5): 1878-1886.

Aleman BM, van den Belt-Dusebout AW, Klokman WJ, Van't Veer MB, Bartelink H, van Leeuwen FE (2003) Long-term cause-specific mortality of patients treated for Hodgkin's disease. J Clin Oncol 21(18): 3431-3439.

Andre MPE, Girinsky T, Federico M, Reman O, Fortpied C, Gotti M, Casasnovas O, Brice P, van der Maazen R, Re A, Edeline V, Ferme C, van Imhoff G, Merli F, Bouabdallah R, Sebban C, Specht L, Stamatoullas A, Delarue R, Fiaccadori V, Bellei M, Raveloarivahy T, Versari A, Hutchings M, Meignan M, Raemaekers J (2017) Early positron emission tomography response-adapted treatment in stage I and II Hodgkin lymphoma: final results of the randomized EORTC/LYSA/FIL H10 trial. J Clin Oncol 35(16): 1786-1794.

Armstrong GT, Liu W, Leisenring W, Yasui Y, Hammond S, Bhatia S, Neglia JP, Stovall M, Srivastava D, Robison LL (2011) Occurrence of multiple subsequent neoplasms in long-term survivors of childhood cancer: a report from the childhood cancer survivor study. J Clin Oncol 29(22): 3056-3064.

Bhakta N, Liu Q, Yeo F, Baassiri M, Ehrhardt MJ, Srivastava DK, Metzger ML, Krasin MJ, Ness KK, Hudson MM, Yasui Y, Robison LL (2016) Cumulative burden of cardiovascular morbidity in paediatric, adolescent, and young adult survivors of Hodgkin's lymphoma: an analysis from the St Jude Lifetime Cohort Study. Lancet Oncol 17(9): 1325-1334.

Borchmann P, Eichenauer DA, Engert A (2012) State of the art in the treatment of Hodgkin lymphoma. Nat Rev Clin Oncol 9(8): 450-459.

Carde P, Burgers JMV, Henry-Amar M, Hayat M, Sizoo W, Van der Schueren E, Monconduit M, Noordijk EM, Lustman-Marechal J, Tanguy A, de Pauw B, Cosset JM, Cattan A, Schneider M, Thomas J, Meerwaldt JH, Somers R, Tubiana M (1988) Clinical stages I and II Hodgkin's disease: a specifically tailored therapy according to prognostic factors. J Clin Oncol 6(2): 239-252.

Cutter DJ, Schaapveld M, Darby SC, Hauptmann M, van Nimwegen FA, Krol AD, Janus CP, van Leeuwen FE, Aleman BM (2015) Risk of valvular heart disease after treatment for Hodgkin lymphoma. J Natl Cancer Inst 107(4): pii: djv008.

De Bruin ML, Sparidans J, van't Veer MB, Noordijk EM, Louwman MW, Zijlstra JM, van den Berg H, Russell NS, Broeks A, Baaijens MH, 
Aleman BM, van Leeuwen FE (2009) Breast cancer risk in female survivors of Hodgkin's lymphoma: lower risk after smaller radiation volumes. J Clin Oncol 27(26): 4239-4246.

Dong H, Robison LL, Leisenring WM, Martin LJ, Armstrong GT, Yasui Y (2015) Estimating the burden of recurrent events in the presence of competing risks: the method of mean cumulative count. Am J Epidemiol 181(7): 532-540.

Dores GM, Metayer C, Curtis RE, Lynch CF, Clarke EA, Glimelius B, Storm H, Pukkala E, van Leeuwen FE, Holowaty EJ, Andersson M, Wiklund T, Joensuu T, van't Veer MB, Stovall M, Gospodarowicz M, Travis LB (2002) Second malignant neoplasms among long-term survivors of Hodgkin's disease: a population-based evaluation over 25 years. J Clin Oncol 20(16): 3484-3494.

Eghbali H, Raemaekers J, Carde P (2005) The EORTC strategy in the treatment of Hodgkin's lymphoma. Eur J Haematol Suppl 66: 135-140.

Engert A, Haverkamp H, Kobe C, Markova J, Renner C, Ho A, Zijlstra J, Král Z, Fuchs M, Hallek M, Kanz L, Döhner H, Dörken B, Engel N, Topp M, Klutmann S, Amthauer H, Bockisch A, Kluge R, Kratochwil C, Schober O, Greil R, Andreesen R, Kneba M, Pfreundschuh M, Stein H, Eich HT, Müller R-P, Dietlein M, Borchmann P, Diehl V (2012) Reducedintensity chemotherapy and PET-guided radiotherapy in patients with advanced stage Hodgkin's lymphoma (HD15 trial): a randomised, openlabel, phase 3 non-inferiority trial. Lancet 379(9828): 1791-1799.

Galper SL, Yu JB, Mauch PM, Strasser JF, Silver B, Lacasce A, Marcus KJ, Stevenson MA, Chen MH, Ng AK (2011) Clinically significant cardiac disease in patients with Hodgkin lymphoma treated with mediastinal irradiation. Blood 117(2): 412-418.

Geenen MM, Cardous-Ubbink MC, Kremer LC, van den Bos C, van der Pal HJ, Heinen RC, Jaspers MW, Koning CC, Oldenburger F, Langeveld NE, Hart AA, Bakker PJ, Caron HN, van Leeuwen FE (2007) Medical assessment of adverse health outcomes in long-term survivors of childhood cancer. JAMA 297(24): 2705-2715.

Girinsky T, van der Maazen R, Specht L, Aleman B, Poortmans P, Lievens Y, Meijnders P, Ghalibafian M, Meerwaldt J, Noordijk E (2006) Involvednode radiotherapy (INRT) in patients with early Hodgkin lymphoma: concepts and guidelines. Radiother Oncol 79(3): 270-277.

Hancock SL, Donaldson SS, Hoppe RT (1993) Cardiac disease following treatment of Hodgkin's disease in children and adolescents. J Clin Oncol 11(7): 1208-1215.

Hodgson DC, Gilbert ES, Dores GM, Schonfeld SJ, Lynch CF, Storm H, Hall P, Langmark F, Pukkala E, Andersson M, Kaijser M, Joensuu H, Fossa SD, Travis LB (2007) Long-term solid cancer risk among 5-year survivors of Hodgkin's lymphoma. J Clin Oncol 25(12): 1489-1497.

Hudson MM, Ness KK, Gurney JG, Mulrooney DA, Chemaitilly W, Krull KR, Green DM, Armstrong GT, Nottage KA, Jones KE, Sklar CA, Srivastava DK, Robison LL (2013) Clinical ascertainment of health outcomes among adults treated for childhood cancer. JAMA 309(22): 2371-2381.

Hull MC, Morris CG, Pepine CJ, Mendenhall NP (2003) Valvular dysfunction and carotid, subclavian, and coronary artery disease in survivors of hodgkin lymphoma treated with radiation therapy. JAMA 290(21): 2831-2837.

Maraldo MV, Dabaja BS, Filippi AR, Illidge T, Tsang R, Ricardi U, Petersen PM, Schut DA, Garcia J, Headley J, Parent A, Guibord B, Ragona R, Specht L (2015) Radiation therapy planning for early-stage Hodgkin lymphoma: experience of the International Lymphoma Radiation Oncology Group. Int J Radiat Oncol Biol Phys 92(1): 144-152.

Morton LM, Dores GM, Curtis RE, Lynch CF, Stovall M, Hall P, Gilbert ES, Hodgson DC, Storm HH, Johannesen TB, Smith SA, Weathers RE, Andersson M, Fossa SD, Hauptmann M, Holowaty EJ, Joensuu H, Kaijser M, Kleinerman RA, Langmark F, Pukkala E, Vaalavirta L, van den Belt-Dusebout AW, Fraumeni Jr JF, Travis LB, Aleman BM, van Leeuwen FE (2013) Stomach cancer risk after treatment for hodgkin lymphoma. J Clin Oncol 31(27): 3369-3377.

Myrehaug S, Pintilie M, Tsang R, Mackenzie R, Crump M, Chen Z, Sun A, Hodgson DC (2008) Cardiac morbidity following modern treatment for Hodgkin lymphoma: supra-additive cardiotoxicity of doxorubicin and radiation therapy. Leuk Lymphoma 49(8): 1486-1493.

Ng AK, Bernardo MP, Weller E, Backstrand KH, Silver B, Marcus KC, Tarbell NJ, Friedberg J, Canellos GP, Mauch PM (2002a) Long-term survival and competing causes of death in patients with early-stage Hodgkin's disease treated at age 50 or younger. J Clin Oncol 20(8): 2101-2108.
Ng AK, Bernardo MV, Weller E, Backstrand K, Silver B, Marcus KC, Tarbell NJ, Stevenson MA, Friedberg JW, Mauch PM (2002b) Second malignancy after Hodgkin disease treated with radiation therapy with or without chemotherapy: long-term risks and risk factors. Blood 100(6): 1989-1996.

Oeffinger KC, Mertens AC, Sklar CA, Kawashima T, Hudson MM, Meadows AT, Friedman DL, Marina N, Hobbie W, Kadan-Lottick NS, Schwartz CL, Leisenring W, Robison LL (2006) Chronic health conditions in adult survivors of childhood cancer. N Engl J Med 355(15): 1572-1582.

Petersen PM, Aznar MC, Berthelsen AK, Loft A, Schut DA, Maraldo M, Josipovic M, Klausen TL, Andersen FL, Specht L (2015) Prospective phase II trial of image-guided radiotherapy in Hodgkin lymphoma: benefit of deep inspiration breath-hold. Acta Oncol 54(1): 60-66.

Raemaekers J, Kluin-Nelemans H, Teodorovic I, Meerwaldt C, Noordijk E, Thomas J, Glabbeke M, Henry-Amar M, Carde P (2002) The achievements of the EORTC Lymphoma Group. European Organisation for Research and Treatment of Cancer. Eur J Cancer 38(Suppl 4): S107-S113.

Schaapveld M, Aleman BM, van Eggermond AM, Janus CP, Krol AD, van der Maazen RW, Roesink J, Raemaekers JM, de Boer JP, Zijlstra JM, van Imhoff GW, Petersen EJ, Poortmans PM, Beijert M, Lybeert ML, Mulder I, Visser O, Louwman MW, Krul IM, Lugtenburg PJ, van Leeuwen FE (2015) Second cancer risk up to 40 years after treatment for Hodgkin's lymphoma. N Engl J Med 373(26): 2499-2511.

Specht L, Yahalom J, Illidge T, Berthelsen AK, Constine LS, Eich HT, Girinsky T, Hoppe RT, Mauch P, Mikhaeel NG, Ng A (2014) Modern radiation therapy for Hodgkin lymphoma: field and dose guidelines from the International Lymphoma Radiation Oncology Group (ILROG). Int $J$ Radiat Oncol Biol Phys 89(4): 854-862.

Swerdlow AJ, Cooke R, Bates A, Cunningham D, Falk SJ, Gilson D, Hancock BW, Harris SJ, Horwich A, Hoskin PJ, Linch DC, Lister TA, Lucraft HH, Radford JA, Stevens AM, Syndikus I, Williams MV (2012) Breast cancer risk after supradiaphragmatic radiotherapy for Hodgkin's lymphoma in England and Wales: a National Cohort Study. J Clin Oncol 30(22): 2745-2752.

Swerdlow AJ, Higgins CD, Smith P, Cunningham D, Hancock BW, Horwich A, Hoskin PJ, Lister A, Radford JA, Rohatiner AZ, Linch DC (2007) Myocardial infarction mortality risk after treatment for Hodgkin disease: a collaborative British cohort study. J Natl Cancer Inst 99(3): 206-214.

Swerdlow AJ, Higgins CD, Smith P, Cunningham D, Hancock BW, Horwich A, Hoskin PJ, Lister TA, Radford JA, Rohatiner AZ, Linch DC (2011) Second cancer risk after chemotherapy for Hodgkin's lymphoma: a collaborative British cohort study. J Clin Oncol 29(31): 4096-4104.

Travis LB, Hill DA, Dores GM, Gospodarowicz M, van Leeuwen FE, Holowaty E, Glimelius B, Andersson M, Wiklund T, Lynch CF, Van't Veer MB, Glimelius I, Storm H, Pukkala E, Stovall M, Curtis R, Boice Jr JD, Gilbert E (2003) Breast cancer following radiotherapy and chemotherapy among young women with Hodgkin disease. JAMA 290(4): 465-475.

van Eggermond AM, Schaapveld M, Lugtenburg PJ, Krol AD, de Boer JP, Zijlstra JM, Raemaekers JM, Kremer LC, Roesink JM, Louwman MW, Aleman BM, van Leeuwen FE (2014) Risk of multiple primary malignancies following treatment of Hodgkin lymphoma. Blood 124(3): 319-327quiz 466.

van Leeuwen FE, Klokman WJ, Hagenbeek A, Noyon R, van den Belt-Dusebout AW, van Kerkhoff EH, van Heerde P, Somers R (1994) Second cancer risk following Hodgkin's disease: a 20-year follow-up study. J Clin Oncol 12(2): 312-325.

van Leeuwen FE, Klokman WJ, Veer MB, Hagenbeek A, Krol AD, Vetter UA, Schaapveld M, van Heerde P, Burgers JM, Somers R, Aleman BM (2000) Long-term risk of second malignancy in survivors of Hodgkin's disease treated during adolescence or young adulthood. J Clin Oncol 18(3): 487-497.

van Nimwegen FA, Schaapveld M, Janus CP, Krol AD, Petersen EJ, Raemaekers JM, Kok WE, Aleman BM, van Leeuwen FE (2015) Cardiovascular disease after Hodgkin lymphoma treatment: 40-year disease risk. JAMA Intern Med 175(6): 1007-1017.

This work is published under the standard license to publish agreement. After 12 months the work will become freely available and the license terms will switch to a Creative Commons AttributionNonCommercial-Share Alike 4.0 Unported License. 